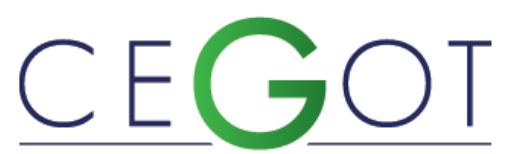

Centro de Estudos de Geografia e Ordenamento do Território
SILVA, LEANDRO RODRIGUES

Universidade de Brasilia

Programa de Pós Graduação em Arquitetura e Urbanismo 70673-405, Brasília, Brasil marcelo.lissa@gmail.com

de Paula, Rubem Oliveira

Universidade de Brasília

Programa de Pós Graduação em Arquitetura e Urbanismo 70673-405, Brasília, Brasil

mscleandro@gmail.com

YAMASHITA, YAEKO

Universidade de Brasília

Programa de Pós Graduação em Arquitetura e Urbanismo 70673-405, Brasília, Brasil

yaekoyamashita@gmail.com

Silva, LUIz Noberto BRANQUINHO

LUCA - Telefônica Data Unit S/A.

03301-000, São Paulo, Brasil

luizn.silva@telefonica.com

\title{
ANÁLISE DA MOBILIDADE INTERURBANA NO BRASIL POR MEIO DE UMA MATRIZ ORIGEM DESTINO DE DADOS DA TELEFONIA MÓVEL
}

ANALYSIS OF INTERURBAN MOBILITY IN BRAZIL USING AN ORIGIN-DESTINATION MATRIX BY MOBILE PHONE BIG DATA

Referência: Silva, Leandro Rodrigues; de Paula, Rubem Oliveira; Yamashita, Yaeko; Silva, Luiz Noberto Branquinho (2021). ANÁLISE DA MOBILIDADE INTERURBANA NO BRASIL POR MEIO DE UMA MATRIZ ORIGEM DESTINO DE DADOS DA TELEFONIA MÓVEL. Revista de Geografia e Ordenamento do Território (GOT), no 22 (Dezembro). Centro de Estudos de Geografia e Ordenamento do Território, p. 52 - 82, dx.doi.org/10.17127/got/2021.22.003

\section{RESUMO}

A mobilidade interurbana a partir de um olhar sistêmico e integrado é pouco estudada no Brasil. Ela compreende os movimentos de pessoas entre cidades, com o objetivo de suprir necessidades não cotidianas, por meio de diferentes modos de transporte, geridos por diferentes dimensões de gestão político-administrativas. O uso de um big data de dados da telefonia móvel no Brasil, de técnicas de modelagem e o cruzamento com dados secundários de diferentes fontes, permitiu um olhar inédito dessa mobilidade, e expõe como uma visão integrada pode contribuir para a melhoria do planejamento. Os resultados demonstram níveis de mobilidade distintos em diferentes regiões brasileiras. A acessibilidade ofertada para a população apresenta diferenças regionais, e as mais de 2 bilhões de viagens individuais realizadas anualmente consideraram diferentes parâmetros para seus deslocamentos e 
escolhas modais, além do custo e do tempo de transporte. O transporte interurbano por automóvel é majoritário (58\%), principalmente pela limitação de oferta de serviços e infraestruturas de outros modos ( $1 \%$ das ligações domésticas possuem mais de um modo de transporte ofertado). Contudo, o transporte aéreo (25\%) e o transporte rodoviário por ônibus (17\%) possuem significativa contribuição na divisão modal da produção do transporte.

Palavras-chave: mobilidade interurbana; transporte interurbano; matriz origem destino; telefonia móvel.

\begin{abstract}
Interurban mobility from a systemic and integrated perspective is not much studied in Brazil. It comprises the movements that take place between cities, with the objective of meeting non-daily needs, through different modals of transport and different dimensions of administrative management. The use of a big data with mobile phone information in Brazil, modeling techniques and the crossing with secondary data from different sources, allowed an unprecedented overview at this mobility, and exposes how this integrated vision can contribute to the improvement of the planning. The results demonstrate a distinct mobility for different Brazilian locations. The accessibility offered to the population presents regional differences, and the data indicate that the more than 2 billion individual trips made annually considered different parameters for their travel and modal choices, in addition to the cost and time of transportation. Intercity transportation by car is the majority (58\%), mainly due to the limited supply of services and infrastructure in other modes (just $1 \%$ of domestic connections have more than one mode of transportation offered). However, air transport (25\%) and road transport by bus (17\%) have a significant contribution to the modal division of transport production.
\end{abstract}

Keywords: interurban mobility; intercity transport; origin-destination matrix; mobile phone.

\title{
1. Introdução
}

Estudos e análises técnicas do transporte de pessoas no Brasil possuem seus escopos comumente delimitados por limites institucionais ou político-administrativos. A bibliografia é vasta sobre estudos de mobilidade em municípios ou regiões metropolitanas legalmente definidas, e ao ampliarmos a escala para o âmbito regional ou nacional, a influência institucional ou político-administrativa fica mais evidente, limitando estudos por modos de transporte (transporte aéreo, transporte rodoviário de passageiros por ônibus, transporte hidroviário de passageiros, etc), muitas vezes associados à recortes institucionais específicos (transporte interestadual, transporte intermunicipal dentro de um Estado, etc). Uma visão ampla e integrada desses diferentes subsistemas de transporte regionais e nacionais atuando em um sistema com objetivo comum era, até recentemente, dificultada pela ausência de 
informações, o que levava pesquisadores a atuarem no escopo onde a informação estava disponível. Porém, tecnologias e dados atualmente disponíveis, como big data de telefonia móvel, permitem ampliar a compreensão do transporte além desses limites, focando as análises na dimensão funcional, e portanto, mais aderente às necessidades da sociedade.

Considerando a oportunidade que a tecnologia nos proporciona, o presente trabalho se propõe a analisar um conceito pouco utilizado: a mobilidade interurbana. $O$ transporte interurbano não pode ser confundido com o deslocamento entre municípios. Comumente há deslocamentos entre municípios em regiões metropolitanas ou para cidades próximas, por exemplo, para realização de atividades cotidianas, como o trabalho e o estudo. Esse tipo de viagem possui recorrência na rotina do indivíduo e sua pendularidade a caracteriza como viagem urbana. Já o transporte interurbano, difere-se principalmente pela sua função. Segundo Crozet (2009), o transporte interurbano possui como indutor as viagens para lazer, as viagens de negócios, e de forma mais generalizada, as viagens discricionárias, ou seja, viagens não essenciais. Associando essa característica à etimologia da palavra, pode-se definir o transporte interurbano como aquele que se realiza entre cidades (aglomerações de pessoas em uma área geográfica, que pode abranger mais de um município), com o objetivo de suprir necessidades não cotidianas.

O presente trabalho foca-se no entendimento de alguns dos fenômenos associados ao transporte interurbano no Brasil, visando subsidiar um planejamento de transporte mais integrado e voltado às necessidades da população, em detrimento de visões isoladas por modos de transporte ou por recortes administrativos associados à gestão, regulação e planejamento legalmente definidos. A hipótese é que uma visão sistêmica permite um diagnóstico mais aderente da mobilidade interurbana da população, e consequentemente orienta ações, identifica oportunidades ou limitações mais precisas tanto para os poderes públicos envolvidos como para as entidades privadas responsáveis pela operação dos serviços de transporte.

Uma inovação tecnológica ascendente como ferramenta de planejamento de transportes permitiu diagnosticar a mobilidade interurbana doméstica no Brasil em termos de acessibilidade e eficiência (atributos descritos nos objetivos da Política Nacional de Transportes - PNT (MTPA, 2018)), além de possibilitar uma visão intermodal e completa de sua demanda. Trata-se da obtenção de uma matriz origem destino (matriz O/D) por meio de 
dados da telefonia móvel, e do decorrente trabalho de tratamento, expansão, e cruzamento de várias bases de dados, cujos principais pontos são apresentados nas seções a seguir.

\section{Uma compreensão sistêmica da rede de deslocamentos interurbanos brasileira}

O transporte interurbano é aquele que se realiza entre cidades, com o objetivo de suprir necessidades não cotidianas. O conceito converge com os principais motivos de viagem verificados em subsistemas de transporte específicos do Brasil, como o transporte rodoviário interestadual de passageiros (ANTT, 2011) ou o transporte aéreo (SAC e EPL, 2015), onde viagens de negócios e de lazer, abrangendo o turismo ou visitas familiares, concentram comumente mais de $85 \%$ dos motivos de viagem desses serviços.

O conceito de transporte interurbano não é comumente utilizado como objeto de análise no Brasil, pois a segregação institucional da gestão e do planejamento de transportes, por modo de transporte, ou por recorte político-administrativo, fazem com que as informações, legislações e, consequentemente, os estudos e análises, sejam agrupadas em subsistemas isolados, por exemplo: o sistema de transporte aéreo, o sistema de transporte rodoviário interestadual de passageiros, os diferentes sistemas de transporte rodoviário intermunicipais (dentro dos Estados) de passageiros, etc.

No presente trabalho, consideraremos estes como subsistemas componentes de um sistema de transporte interurbano de pessoas no Brasil, pois tratam-se de recortes estabelecidos no ponto de vista legal, para um conjunto de serviços e infraestruturas que possuem, no ponto de vista funcional, o mesmo papel para a população: ofertar oportunidades de deslocamentos interurbanos, como aponta trabalho de Silva et ali (2019). Essa visão sistêmica aproxima-se da visão dos usuários, que perante um desejo de viagem, estuda as opções de deslocamento de forma estruturada ou não, independente do recorte institucional dos subsistemas ofertados.

Contudo, traduzir o conceito de transporte interurbano para a realidade exige algumas considerações. Além de nos desligarmos, por hora, dos recortes institucionais de gestão, planejamento e regulação, devemos considerar a "cidade" também com seu conceito mais 
puro, senão original, do latim: civitas, ātis - cidade, reunião de cidadãos. O destaque é necessário para não nos prendermos às divisões político-administrativas de municípios, ou ao estabelecimento de limites de extensão ou tempo de deslocamento para conceituarmos a função de um transporte. Logo, a tarefa primária para conseguirmos enxergar o transporte interurbano brasileiro é tentar definir limites reais das cidades, de forma que seja possível separar os fluxos internos dessas áreas (urbanos, pendulares e essenciais), dos interurbanos (discricionários).

Um olhar mais próximo à funcionalidade das aglomerações urbanas é dado pelo estudo do IBGE (2016) sobre "Arranjos populacionais e Concentrações Urbanas do Brasil", que define arranjos populacionais como o agrupamento de dois ou mais municípios entre os quais existe uma forte integração populacional, medidos pelos movimentos pendulares para trabalho e estudo e/ou pela contiguidade da mancha urbanizada. Baseado nessa visão, vem crescendo no âmbito do planejamento de transportes nacional a utilização das Unidades Territoriais de Planejamento - UTP, que são aglomerações de municípios que possuem fortes relações cotidianas entre si, agrupando deslocamentos pendulares de natureza urbana, de forma que consigamos considerar que os deslocamentos entre as UTPs são os de natureza tipicamente interurbana. Esse conceito e o detalhamento dessas unidades é explorado em publicações como o Silva et ali (2019), no Plano Aeroviário Nacional 2018-2038 (MTPA, 2018c), e em divulgações do Plano Nacional de Logística - PNL 2035 (EPL, 2020a e EPL, 2021).

\section{Uso de dados da telefonia móvel no planejamento de transporte}

A construção de matrizes de origem destino precisas é essencial para o planejamento de sistemas de transporte. Quanto maior a acurácia da matriz, maior a capacidade de direcionar ações e investimentos para ampliar a eficiência dos sistemas de transporte. Spiess, (1987), Van Zuylen e Willumsen, (1980) e Cascetta e Nguyen (1988) utilizam-se de métodos estatísticos para extrapolação de dados de contagem de veículo e movimentos, e apresentam ampla bibliografia sobre o tema. Os métodos de contagem e a extrapolação dos dados consistiam nos principais meios de formação dessas matrizes O/D. 
Com a possibilidade de uso de dados de telefonia, advinda da crescente utilização de dispositivos móveis, ampliaram-se as possibilidades e o volume das contagens da amostra possíveis. De acordo com Calabrese et ali (2013), a utilização de dados de telefonia móvel permite que pesquisadores examinem novas possibilidades sob perspectivas alternativas, com custos mais baixos de obtenção de dados, amostras maiores, atualizações mais frequentes e coberturas espacial e temporal mais amplas. Esse mesmo autor lista pontos negativos inerentes à utilização de dados de telefonia móvel, tais como falta de informações socioeconômicas, dificuldade em garantir aleatoriedade das amostras e complexidade de tratamento dos dados. A Tabela 1 sintetiza os principais pontos negativos e positivos da utilização.

É importante observar como a qualidade destas fontes de informação tende a evoluir. Entrevistas físicas de conteúdo pouco extenso têm migrado para formatos não presenciais (questionários online compartilhados via email, SMS ou outros canais digitais). Embora as taxas de resposta destes canais ainda limitem significativamente as amostras, reduções de custo podem ser alcançadas neste processo.

Tabela 1 - Síntese comparativa de pontos fortes e fracos de diferentes fontes dados para formação de matriz O/D

\begin{tabular}{lccc}
\hline & $\begin{array}{c}\text { Pesquisas } \\
\text { tradicionais } \\
\text { (entrevistas físicas) }\end{array}$ & $\begin{array}{c}\text { Dados } \\
\text { secundários }\end{array}$ & $\begin{array}{c}\text { Big Data da } \\
\text { telefonia móvel }\end{array}$ \\
\hline Confiabilidade & média & baixa & alta \\
\hline Amostra & pequena e incompleta & incompleta & grande \\
\hline Custo & alto & baixo & médio \\
\hline Tempo de realização & demorado & rápido & rápido \\
\hline Periodicidade & baixa & baixa & alta \\
\hline Informações Socioeconômicas & muitas & poucas & média \\
\hline Complexidade de tratamento dos & baixa & média & alta \\
dados & & & \\
\hline
\end{tabular}


Já os dados secundários apresentam tendência de se tornarem mais abundantes, devido ao avanço do fenômeno da internet das coisas e da transformação digital das empresas, levando a possibilidade de que cada corporação colete e armazene extensivamente dados próprios e de terceiros, mais completos e recentes, aumentando a confiabilidade dos dados secundários, principalmente nos transportes.

No caso dos dados de telefonia móvel observam-se mudanças nos últimos anos. Com aumento expressivo do uso dos serviços nos diferentes perfis da sociedade, aumenta-se a amostra, a aleatoriedade, e a capacidade de medição do comportamento dos usuários.

Qualquer tipo de pesquisa deve garantir que seus dados permitam obter conclusões sobre o comportamento da população em estudo, não refletindo somente o comportamento da amostra pesquisada. Para se certificar desta representatividade o big data de telefonia móvel deve compreender em profundidade a distribuição espacial e sociodemográfica da sua base de usuários. Grupos de usuários com alto registro de pernoite em uma região podem ser assignados como residentes, e por associação direta aos locais, pode-se inferir dados socioeconômicos destes grupos. Combine-se a este processo a incorporação de informações tipicamente cadastrais como idade e gênero, e é possível construir a visão das distribuições espacial e sociodemográficas mencionadas.

A utilização de dados de telefonia móvel na determinação de padrões de deslocamento de pessoas conta com literatura abrangente, principalmente sobre deslocamentos urbanos e metropolitanos. Calabrese et ali (2013) e Alexander et ali (2015) demonstram o potencial da utilização de dados de telefonia móvel na construção de metodologia para avaliação de deslocamentos aplicada à região metropolitana de Boston, Estados Unidos. Nabavi et ali (2015) apresentam estudo do comportamento dos fluxos de origem e destino por meio de dados de telefonia móvel na região de Paris e seus subúrbios, na França, para diferentes modos de transportes. Iqbal et ali (2014) propõem uma metodologia que utiliza CDR (Call Detail Record) na formação de uma matriz O/D, a qual aplicam à região de Daca, Bangladesh. Apesar da ampla utilização de dados de telefonia móvel para identificação de padrões de deslocamento intra-urbanos, há, ainda, poucas referências em se tratando de deslocamentos interurbanos. Mamei et ali (2019) utilizaram dados de telefonia móvel para estimar padrões e quantidades de deslocamentos interubanos em três regiões da Itália, Piemonte, Emília- 
Romanha e Lombardia. Wang et ali (2015) utilizam-se desses dados para construir uma matriz O/D em nível regional no Senegal.

O procedimento para identificação de deslocamentos por meio de dados da telefonia móvel consiste no mapeamento dos Call Detail Record (CDR's), que correspondem aos registros do canal de voz, além dos $X$ Detail Record (XDR's), referentes aos registros de transmissão e recepção de dados. Parâmetros da cobertura de rede permitem uma localização aproximada dos aparelhos telefônicos durante a conexão com as antenas (em geral algumas centenas de metros de precisão espacial). Como para a escala geográfica do presente trabalho o agrupamento de Origens e Destinos nunca é menor que um município, a localização é extremamente precisa, permitindo a identificação de deslocamentos interurbanos entre municípios ou aglomerações urbanas que constituem as UTPS.

É importante frisar que os dados são trabalhados em um big data que garante a anonimização de registros pessoais.

\section{Obtenção da matriz origem destino}

A obtenção da matriz O/D de deslocamentos interurbanos no Brasil para o ano base 2017 iniciou-se com os produtos do Termo de Execução Descentralizada (TED) firmado no ano de 2018 entre o Ministério dos Transportes, Portos e Aviação Civil - MTPA (atual Ministério da Infraestrutura) e a Universidade Federal de Santa Catarina - UFSC, onde um de seus objetos compreendia o "Desenvolvimento de uma matriz O/D de passageiros em âmbito nacional para identificação dos reais desejos de viagem contemplados ou não pelo transporte aéreo" (MTPA, 2018b). A UFSC, por meio de licitação, contratou a empresa Telefónica S/A como fornecedora dos dados para a Matriz, trabalhando de forma conjunta com a empresa e com o MTPA para delimitar a metodologia adequada, dado o ineditismo dessa pesquisa em âmbito nacional, e mesmo o ineditismo, no cenário internacional, da aplicação dessa tecnologia em uma escala tão ampla.

A empresa selecionada possuía em 2017 cerca de 31\% do market share da telefonia móvel brasileira (ANATEL, 2020). A amplitude dessa amostra permitiu a popular um big data capaz de fornecer informações de deslocamentos agregados, que são a semente para a elaboração 
da matriz O/D. A metodologia detalhada de tratamento dos dados constam nos documentos produtos do TED citado (Telefônica, 2019 e Labtrans, 2019), aqui apresentados somente os aspectos mais relevantes para a compreensão do presente trabalho. Os dados provenientes dessa pesquisa são públicos (Labtrans, 2020).

A amostra de dados válidos para a construção da matriz O/D, após anonimização, agrupamento e tratamentos de qualidade da informação, contou com mais de 26 milhões de usuários válidos, que realizaram 219 milhões de viagens interurbanas no ano de 2017. Perante essa amostra, verifica-se o benefício dessa forma de obtenção de dados perante outros meios de pesquisa tradicionais. Além da confiança estatística, amostras desta magnitude permitem mensurar eventos de baixa frequência, que usualmente são modelados em pesquisas tradicionais. Uma pesquisa presencial com similar amostra, e amplitude nacional, se mostraria economicamente inviável. Isso explica, em parte, o porquê de até então não encontrarmos na bibliografia técnica, científica ou institucional uma visão abrangente e intermodal dos deslocamentos interurbanos no Brasil como a apresentada a diante. A margem de erro estatístico da amostra por UF é, em média, de 0,14\% para um nível de confiança de $99 \%$.

As origens ou destinos para cada deslocamento interurbano na matriz foram contabilizados quando os usuários se apresentaram estacionários em uma UTP por um período mínimo de 6 horas, de forma a não se confundirem origens e destinos com fluxos de passagem.

Após alocação dos fluxos, os dados passaram por um primeiro processo de extrapolação. Essa etapa não se caracteriza como a extrapolação da amostra para o universo (Brasil), e sim, para o recorte de população pertencente aos municípios com cobertura da Telefônica S/A dentro do conjunto de municípios que fazem parte das UTPs pré-definidas. A extrapolação é linear em relação à população, com fatores aplicados a nível de município, expandindo as amostras para os valores que o IBGE projetava para as populações em 2017. Importante salientar que as UTPs pré-definidas para essa etapa abrangiam 4827 municípios brasileiros, e 93\% da população.

Como resultado parcial, temos uma matriz de fluxos interurbanos entre UTPs, com segregação em "fluxos aéreos" e "fluxos não aéreos" (Labtrans, 2020). Essa separação foi obtida considerando o intervalo de tempo em que um usuário aparece em diferentes UTPs, 
em comparação à uma matriz de tempo de corte de referência. Essa é a base bruta de dados provenientes da telefonia móvel, com cerca de 1,6 bilhão de deslocamentos anuais, em mais de 66 mil ligações entre as UTPs.

\section{Tratamento e expansão da matriz}

Visando a obtenção de uma matriz origem destino intermodal e representativa para o Brasil, foi realizada a expansão da matriz O/D bruta de dados provenientes da telefonia móvel e a estimativa da divisão modal por meio do cruzamento com outras bases de dados secundários e modelos. O trabalho consistiu nas seguintes etapas:

1. Expansão da matriz para as UTPs com cobertura parcial, por meio de modelagem.

2. Expansão da matriz para as UTPs não cobertas e demais municípios do Brasil, por meio de modelagem e da identificação de fluxos interurbanos em outras bases de dados.

3. Divisão modal, por meio de levantamento, tratamento e consolidação de dados para os modos de transporte rodoviário por ônibus, ferroviário e aquaviário.

Para possibilitar a aplicação das etapas, foram levantados dados de diversas fontes, como Instituto Brasileiro de Geografia e Estatística (IBGE, 2017); Agência Nacional de Transporte Terrestre (ANTT, 2020 e ANTT, 2018); Agência Nacional de Transporte Aquaviário (ANTAQ e UFPA, 2018); Agência Nacional de Aviação Civil (ANAC, 2020); Banco de Informações de Movimento de Tráfego Aéreo - BIMTRA e; Observatório Nacional de Transporte e Logística ONTL (EPL, 2020). A partir desses dados, procedeu-se avaliação de consistência, representatividade e tratamento. Todos os dados foram trazidos para o ano base -2017 com auxílio de taxas de crescimento específicas de cada fonte, quando necessário, e todos os fluxos foram agrupados nos formatos de O/D por UTP.

Dentre diferentes análises, identificou-se a necessidade de tratamento de outliers na base de dados da pesquisa "Redes e Fluxos do Território - Ligações Rodoviárias e Hidroviárias 2016" (IBGE, 2017a), visto que em cerca de $8 \%$ das UTPs foram verificadas taxas de frequência de saídas de ônibus rodoviários por habitante acima de 2,5 Desvios Padrão dentro da amostra, com valores altos e um viés claramente geográfico. Fez-se necessário, portanto, utilizar parte da base de dados da pesquisa em questão para modelagem com o objetivo de estimar a 
frequência de viagens interurbanas por ônibus rodoviário, baseada no número de viagens pelo modo rodoviário obtido com os dados da telefonia móvel.

A expansão da matriz para municípios em UTPs com cobertura parcial, e para municípios e UTPs não cobertas na pesquisa (itens 1 e 2 da relação de etapas), deu-se por meio da estimativa de uma demanda gerada por UTP ou município, e a sequente distribuição em valores proporcionais aos estimados por meio de um modelo gravitacional.

A estimativa de geração de viagens utiliza como variáveis independentes a população do município ou UTP e o Índice de Integração, que representa a oferta do conjunto de infraestruturas e serviços de transporte interurbano na região e sua relação com os demais do território nacional, calculado com ferramental e conceito da sintaxe espacial, conforme procedimento detalhado em Silva e Holanda (2019).

A Equação 1 apresenta o modelo desenvolvido por meio de regressão com o Método dos Mínimos Quadrados - MMQ (Woolridge, 2010). Os parâmetros da regressão constam na Tabela 2. Dentre as equações testadas, optou-se pela seguinte, sem intercepto, considerando como lógica a hipótese de casos onde a população e a integração (oferta de infraestrutura e serviços) sejam nulos, o número de viagens interurbanas também seria nulo. Em outras palavras, não há valor médio esperado para viagens interurbanas em populações nulas ou locais sem infraestrutura de transportes.

$$
\text { Total }_{i}=\left(7,09 \cdot P O P_{i}\right)+\left(9,48 \cdot 10^{4} . \text { IIntegração }\right)
$$

(Equação 1)

Onde:

Total $_{i}$ - Total de viagens a partir e para a UTP ou município "i".

$P O P_{i}$ - População da UTP ou município "i".

IIntegração - Índice de Integração da UTP ou município "i".

O Índice de Integação possui grandeza variável entre 0,16 e 126,45, com média de 4,12 na amostra. Considerando o valor alto do parâmetro encontrado para essa variável na equação utilizada, observou-se que ela pesa tanto quanto a população nos resultados do modelo.

A estimativa de distribuição de viagens considera um modelo gravitacional (Bates, 2000) desenvolvido e calibrado com a base de dados da telefonia móvel e apresentado na Equação 
2, com expoente da impedância do transporte (distância da viagem) variável. Este expoente, por sua vez, foi também modelado com o Método dos Mínimos Quadrados - MMQ (Woolridge, 2010). Os parâmetros da regressão constam na Tabela 2.

$$
\begin{gathered}
\text { TotalRe }_{i, j}=\left(4,99 \cdot 10^{-2} \cdot \frac{P O P_{i} \cdot P O P_{j}}{D_{i, j}^{e}}\right)-\left(1,67 \cdot 10^{5} \cdot \operatorname{LN}\left(D_{i, j}\right)\right)+\left(7,53 \cdot 10^{4} \cdot \operatorname{LN}\left(\text { PIBTur }_{i}+\text { PIBTur }_{j}\right)\right) \\
e=8,53 \cdot 10^{-1}+\left(3,97 \cdot 10^{-2} \cdot \operatorname{LN}\left(P I B_{i} \cdot P I B_{j}\right)+\left(5,07 \cdot 10^{-2} \cdot \frac{P^{2}+P O P_{i}}{T_{i, j}}\right)\right.
\end{gathered}
$$

Onde:

TotalRefi,j - É a demanda de referência calculada entre os municípios ou UTP "i" e "j".

$P O P_{i}$ - É a população do município ou UTP "i".

$P O P_{j}$ - É a população do município ou UTP "j".

$P I B_{i}-E$ É o Produto Interno Bruto do município ou UTP "i".

$P I B_{j}$ - É o Produto Interno Bruto do município ou UTP "j".

PIBTur - É o Produto Interno Bruto dos serviços turísticos no município ou UTP "i".

PIBTur - É o Produto Interno Bruto dos serviços turísticos no município ou UTP "j".

$T_{i, j}$-É o tempo de viagem médio entre "i" e "j".

$D_{i, j}$ - É a distância rodoviária entre "i" e "j".

$e=$ É o expoente variável da impedância de transporte considerada no modelo gravitacional.

Tabela 2 - Coeficientes de correlação, determinação, testes F e testes estatísticos (teste t)

\begin{tabular}{|c|c|c|c|}
\hline Equação & 1 & 2 & $2(e)$ \\
\hline R múltiplo & 0,89 & 0,79 & 0,54 \\
\hline $\mathrm{R}^{2}$ & 0,79 & 0,63 & 0,3 \\
\hline$R^{2}$ ajustado & 0,79 & 0,63 & 0,3 \\
\hline Erro padrão & 3818933 & 398529 & 0,22 \\
\hline F de significância & $7,60 \mathrm{E}-183$ & 0 & 0 \\
\hline Interseção & - & 0 & $1,40 \mathrm{E}-175$ \\
\hline Var 1 & $9,40 \mathrm{E}-52$ & $4,13 E-187$ & $6,33 \mathrm{E}-173$ \\
\hline Var 2 & 6,39E-46 & 1,87E-206 & 1,35E-65 \\
\hline
\end{tabular}
dos modelos de regressão linear múltiplos

A estimativa para municípios não cobertos pela base de dados proveniente da telefonia móvel foi realizada para todas as ligações O/D mapeadas nas bases de dados acessórias, considerando tanto a existência de ligações por transporte aéreo (ANAC, 2020 e; DECEA 2016), por transporte rodoviário por ônibus (IBGE, 2017), aquaviário (ANTAQ e UFPA, 2018; 
e IBGE, 2017) e ferroviário (EPL, 2020). Quatro municípios que não apresentaram nenhuma ligação evidente nessas bases. Para eles, foi estimada a demanda para uma ligação hipotética para o município com maior relação hierárquica conforme os dados do estudo "Regiões de influência das cidades - REGIC" (IBGE, 2007).

As estimativas modeladas foram realizadas para o total de viagens de cada par O/D. A partir das bases de dados de referência para os transportes coletivos (aéreo, aquaviário e ferroviário) foi possível observar dentro de cada ligação qual a demanda seria destinada à esses modos, sendo que a demanda restante foi considerada como rodoviária (automóveis e ônibus).

Para dividir as demandas entre ônibus e automóveis em cada ligação, utilizou-se os dados da pesquisa do IBGE de ligações rodoviárias (IBGE, 2017), que traz a frequência de saídas de viagens rodoviárias por ônibus e por município e; dados de ocupações médias para ônibus rodoviários disponíveis no sistema MONITRIIP (ANTT, 2020). Com esses dados, foi calculada a demanda por ônibus, sendo que o valor restante da demanda rodoviária foi considerado como viagens do modo rodoviário por automóvel.

A congregação de todos esses componentes forma a Matriz Origem-Destino Interurbana de transporte doméstico de pessoas para todo o território brasileiro em 2017, observada na Figura 1.

A expansão geográfica da matriz por meio da aplicação dos modelos desenvolvidos fez com que o número de ligações O/D presentes na matriz bruta aumentasse de 66.791 para 75.057 (+12\%), e um acréscimo de $19 \%$ na demanda. Isso demonstra que os dados originais provenientes da telefonia móvel nas UTPs já concentravam a principal parcela do transporte. 


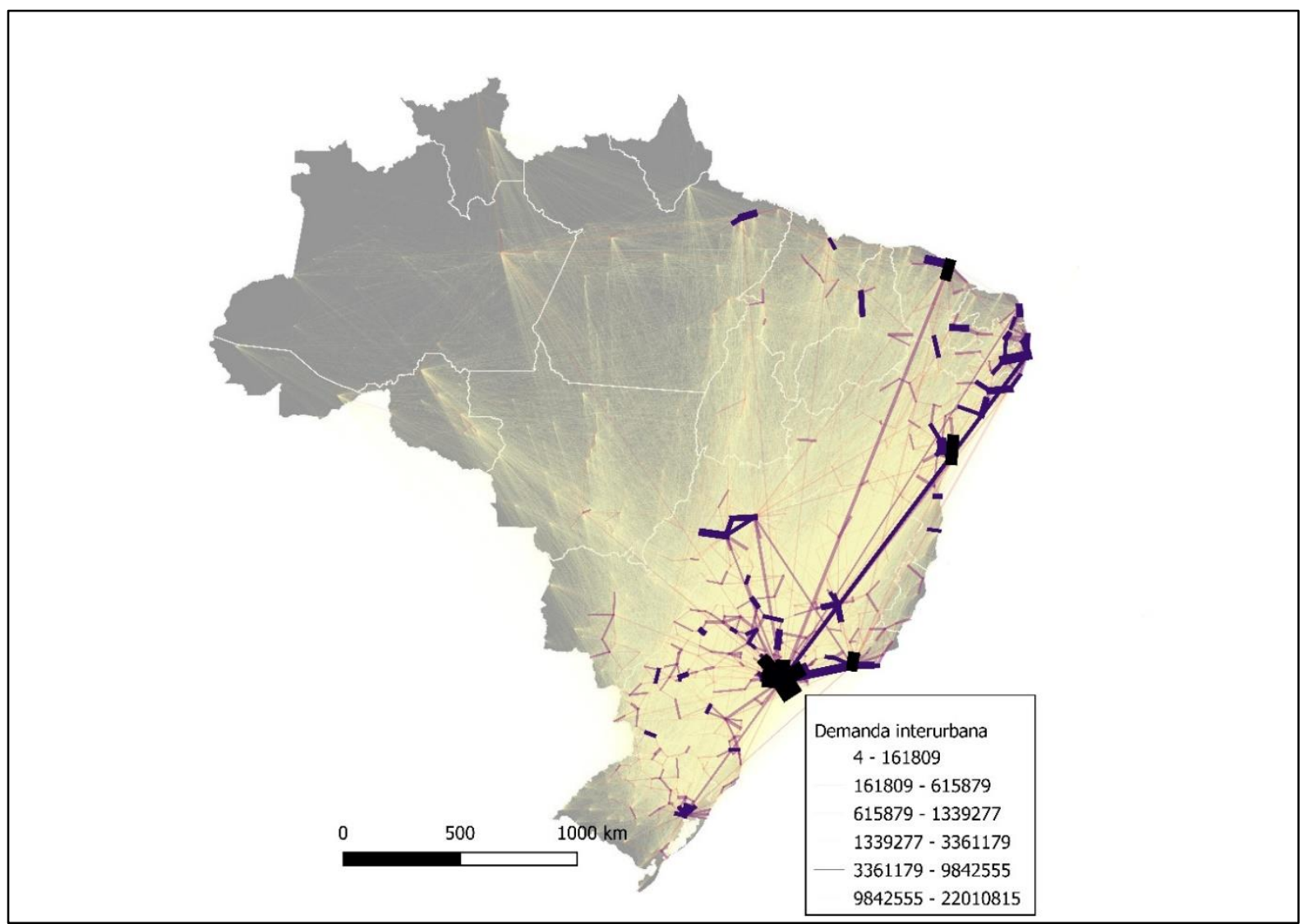

Figura 1 - Fluxos interurbanos no Brasil (2017)

\section{Diagnóstico da mobilidade interurbana no Brasil}

O transporte interurbano no Brasil, dentro do conceito adotado no presente trabalho (para todos os modos de transporte ofertados, e independente da gestão institucional), foi responsável pela movimentação de 2,01 bilhões de pessoas no Brasil no ano de análise (2017), sendo o transporte rodoviário o mais representativo dentre os modos, com $95,80 \%$ das pessoas transportadas (74\% por automóvel particular, e $21,80 \%$ por ônibus de viagens, intermunicipais e interestaduais).

As principais demandas concentram-se nas ligações de São Paulo para cidades próximas e para as demais capitais do País, como observado na Figura 1. É possível notar também as fortes ligações das capitais do Nordeste ${ }^{1}$ com redes de cidades que constituem polos regionais, além de altas demandas entre cidades do interior de São Paulo e entre cidades do

\footnotetext{
${ }^{1}$ Para as análises regionais, utilizou-se a divisão regional do Brasil em Grandes Regiões: Norte, Nordeste, CentroOeste, Sudeste e Sul, conforme IBGE (2017).
} 
sudoeste Mineiro. A região sudeste concentra $41 \%$ da demanda por transporte interurbano nacional.

A distribuição modal do transporte interurbano doméstico brasileiro (Tabela 3) acompanha a tendência de oferta de infraestruturas e serviços, com alta concentração rodoviária, fruto do histórico de desenvolvimento da rede de conexões entre as cidades brasileiras. Os demais modos de transporte presentes, mostram-se como opções específicas para regiões com oferta limitada (o caso do transporte hidroviário), ou como preferências para deslocamentos rápidos e de longa distância (transporte aéreo).

Tabela 3 - Distribuição do transporte interurbano doméstico brasileiro por modo de transporte (2017)

\begin{tabular}{|c|c|c|c|c|c|}
\hline \multicolumn{2}{|c|}{ Modo de transporte } & $\begin{array}{c}\text { Demanda por } \\
\text { transporte } \\
\text { interurbano (milhões } \\
\text { de viagens } \\
\text { individuais) }\end{array}$ & Subtotal & $\begin{array}{l}\text { \% modos } \\
\text { coletivos }\end{array}$ & $\%$ geral \\
\hline \multirow{4}{*}{ Coletivos } & Transporte Aéreo & 76,8 & \multirow{4}{*}{522,9} & $14,7 \%$ & $3,8 \%$ \\
\hline & $\begin{array}{l}\text { Transporte } \\
\text { Rodoviário por } \\
\text { ônibus (interestadual } \\
\text { e intermunicipal) }\end{array}$ & 438,5 & & $83,9 \%$ & $21,8 \%$ \\
\hline & $\begin{array}{l}\text { Transporte } \\
\text { Ferroviário }\end{array}$ & 1,3 & & $0,2 \%$ & $0,2 \%$ \\
\hline & $\begin{array}{l}\text { Transporte } \\
\text { Hidroviário }\end{array}$ & 6,2 & & $1,2 \%$ & $0,3 \%$ \\
\hline Privado & Automóvel particular & $1.488,6$ & $1.488,6$ & & $74,0 \%$ \\
\hline Total & & $2.011,5$ & $2.011,5$ & & \\
\hline
\end{tabular}

Observou-se concentração da demanda interurbana brasileira nas ligações curtas, como sugere os modelos gravitacionais de distribuição de viagens (Philbrick, 1971). As ligações de até $100 \mathrm{~km}$ concentram 60,77\% da demanda interurbana. Isso ajuda a explicar a predominância do modo rodoviário como principal, visto que o transporte aéreo, no estágio tecnológico atual, não se expressa como uma alternativa viável para viagens curtas. Além disso, a rede rodoviária brasileira apresenta uma capilaridade no território brasileiro superior à qualquer outro modo de transporte, proporcionando acesso, de e para, quase todas as cidades do Brasil. A Figura 2 apresenta a distribuição da demanda conforme a distância da ligação O/D. 


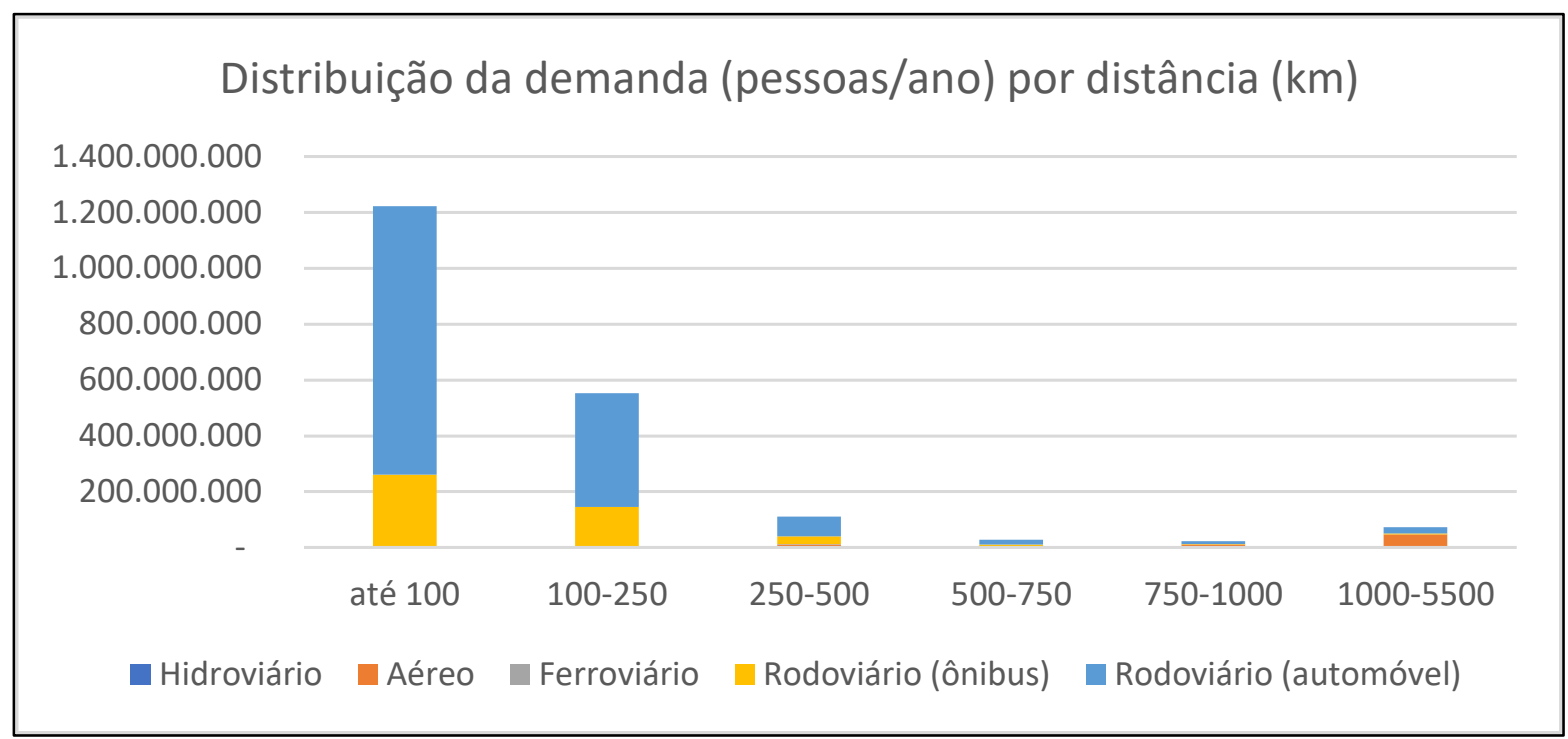

Figura 2 - Distribuição da demanda interurbana brasileira (em pessoas/ano) por distância (em km) nas ligações

A divisão modal do transporte é variável conforme a distância, como visto na Figura 3. A participação percentual do transporte aéreo cresce à medida que as ligações são mais distantes, até atingir 65\% da demanda para ligações acima de $1000 \mathrm{~km}$. Esse comportamento é similar às matrizes modais dos Estados Unidos e do Reino Unido, conforme dados de Yai et ali (2015), e significativamente diferente da matriz modal do Japão, que apresenta o transporte ferroviário como bastante representativo tanto em ligações curtas como longas.

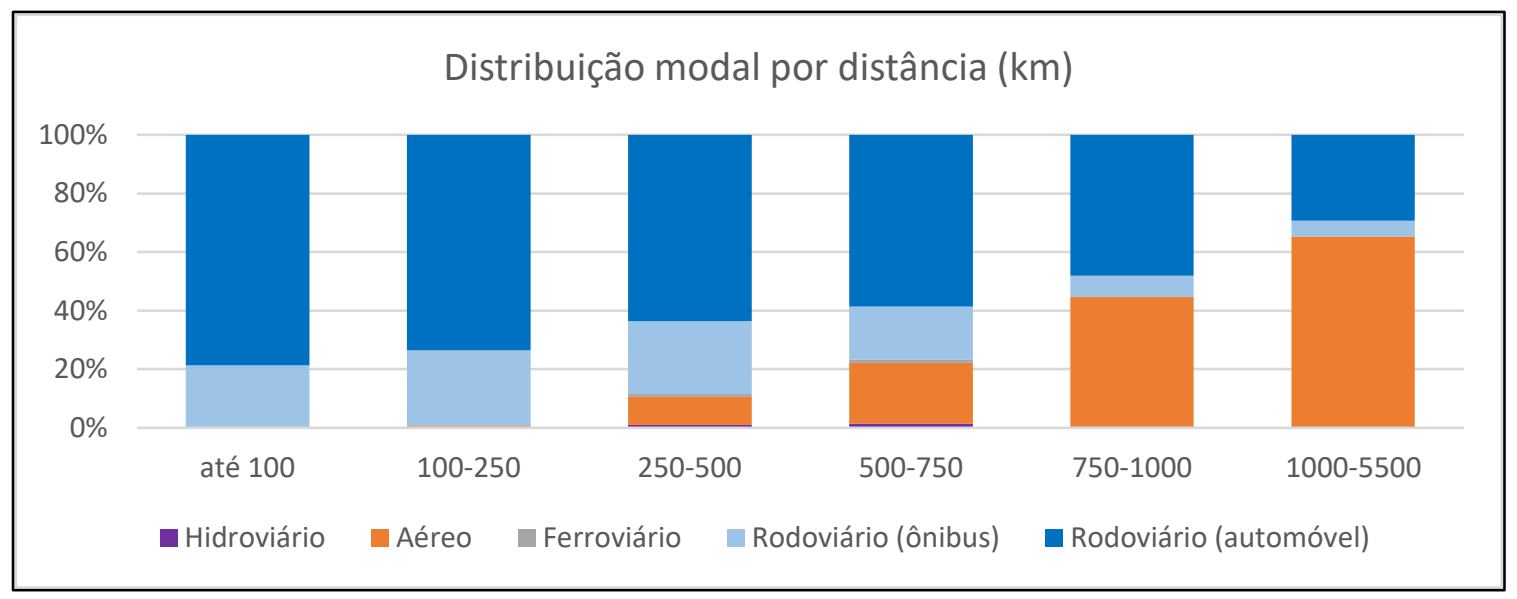

Figura 3 - Distribuição da demanda interurbana brasileira (em pessoas/ano) por distância (em km) nas ligações

Observa-se que nas ligações interurbanas acima de $250 \mathrm{~km}$ existe distribuição da demanda entre os modos de transporte aéreo e rodoviário, que fica mais evidente a partir de $500 \mathrm{~km}$. 
Pode-se dizer que perante os atuais atributos de oferta e características destes modos de transporte, as ligações interurbanas a partir de $500 \mathrm{~km}$ são as que podem apresentar real potencial de competitividade entre esses modos.

Considerando a aderência de cada modo de transporte à distâncias diferentes, um olhar mais preciso da divisão modal do transporte interurbano se dá quando comparamos a produção do transporte. Nesse sentido, a Figura 4 apresenta a divisão modal em termos de RPK (Revenue Passenger Kilometers), que se dá pela multiplicação da quantidade de pessoas transportadas pela extensão da ligação, em quilômetros. Nesse espectro, verifica-se que os modos de transporte rodoviário por automóvel, o transporte aéreo e o transporte rodoviário por ônibus possuem contribuições significativas para o transporte interurbano nacional.

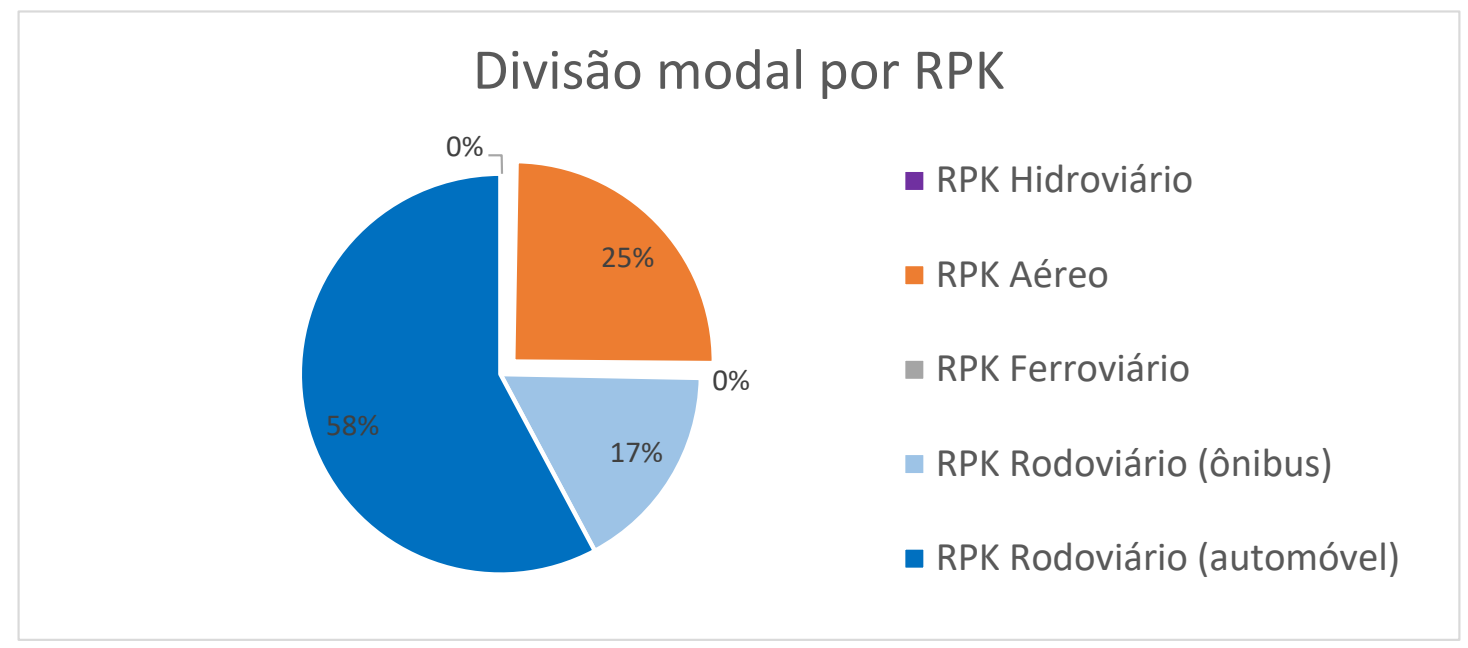

Figura 4 - Divisão modal do transporte interurbano de pessoas no Brasil (doméstico).

A avaliação da divisão modal associada à extensão da ligação evidencia algumas preferências dos usuários e indica atributos que interferem na escolha modal. Porém, tais decisões consideram uma série de fatores como o tempo, custo (Lieshout, 2012), disponibilidade, quantidade de acompanhantes na mesma viagem, e outros mais subjetivos como a conveniência e o conforto (Dinwoodie, 2001). Para possibilitar uma compreensão mais ampla desses aspectos, os dados da matriz foram tratados e alocados, conforme o modo de transporte, em uma rede formada pelo conjunto de infraestruturas e serviços disponíveis, o que permitiu a estimativa de tempo dos deslocamentos em cada modo, e seus custos. 
Os dados dessa rede são provenientes de diferentes fontes. Para o modo de transporte aéreo considerou-se a rede de oferta a da aviação comercial regular brasileira (ANAC, 2020a). Logo, para fins de análises comparativas entre modos e opções de oferta, as viagens de aviação geral e executiva foram desconsideradas, por se tratar de serviço privado e limitado à pequena parcela da população.

Os dados de custos para o transporte aéreo foram calculados conforme as tarifas médias disponibilizadas pela ANAC (2020b), e utilizando Yields médios por par de UFs como parâmetro para estimativa de custos de ligações eventualmente não contempladas nos microdados.

Para o transporte rodoviário por ônibus e para o transporte hidroviário, foram utilizados dados de custos e tempos da pesquisa de ligações rodoviárias e hidroviárias (IBGE, 2017). Os dados de tempo para viagens por automóvel foram calculados com simulação na rede rodoviária brasileira em software SIG (Sistema de Informações Geográficas), considerando também como parâmetros de calibração dessa rede, dados de sistemas online e colaborativos de roteirização que consideram informações de deslocamentos reais de deslocamentos (como Gmaps ${ }^{\circledR}$ e OpenStreeetMap). Para o cálculo dos custos para viagens por automóvel foi considerado o custo médio de $\mathrm{R} \$ 0,66$ por km, adotado como parâmetro médio nacional no Plano Nacional de Logística 2035 (EPL, 2020c). Esse custo considera tanto custos variáveis, como combustível, lubrificantes, pneus e manutenção, como uma parcela referente ao capital.

Já para o tempo e custo do modo ferroviário, utilizou-se os dados das duas ferrovias que compõem esse subsistema na ótica interurbana: Estrada de Ferro Carajás (Vale, 2020a) e Estrada de Ferro Vitória Minas (Vale, 2020b).

Foram utilizados dados representativos para o ano base da matriz (2017). Aos tempos de viagem dos modos coletivos, foram acrescidos tempos médios de espera e de parada, conforme parâmetros da regulamentação da ANTT (2020b) e da pesquisa de qualidade da Secretaria Nacional de Aviação Civil (MInfra, 2020), para viagens por ônibus e por aeronaves, respectivamente. Com isso, foi possível avaliar a questão do tempo de viagem em uma ótica próxima à dos usuários. 
Com as demandas, custos, tempos e disponibilidades de cada modo de transporte nas ligações interurbanas, foi possível calcular indicadores de tempo médio ponderado e custo médio ponderado, que representam os tempos médios de cada UTP, UF ou região, considerando como ponderador as demandas de cada ligação. Logo, os resultados apontam as impedâncias de viagem conforme as principais necessidades das populações locais, apresentando-se como indicadores de acessibilidade e eficiência do transporte interurbano de pessoas no Brasil. Os dados da Figura 5 indicam, por exemplo, que enquanto algumas populações possuem um tempo médio de deslocamento interurbano de até 49,4 horas para alcançar seus destinos mais demandados, outras, os fazem com 0,3 hora.

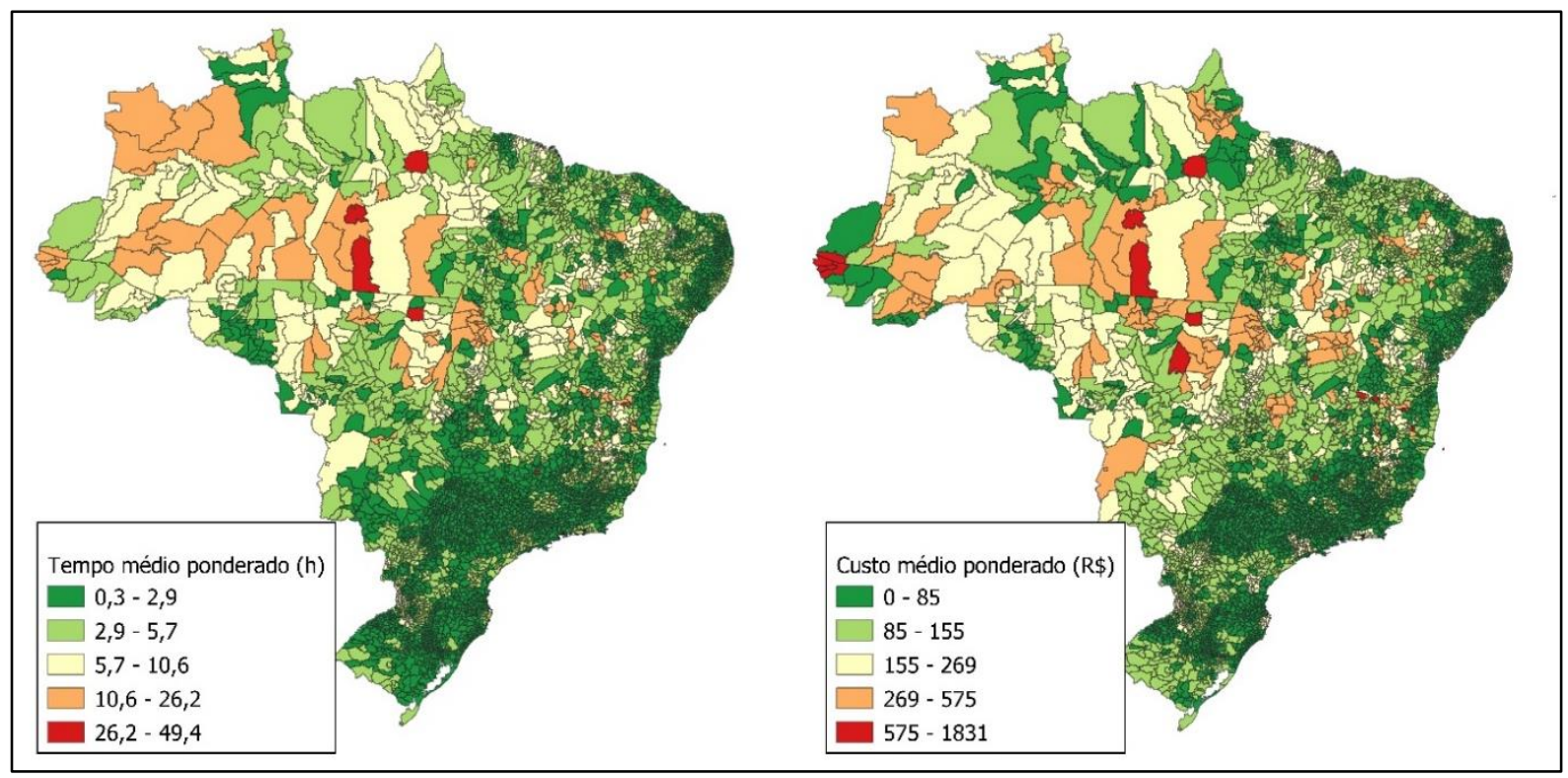

Figura 5 - Tempo (h) e custo (R\$) médios ponderados pela demanda - viagens interurbanas, por UTP.

A Figura 5 demonstra que populações localizadas nas regiões Sul, Sudeste, e áreas litorâneas, apresentam tempos médios e custos para suas demandas interurbanas significativamente inferiores que os das populações do Norte do país e de parte do Centro-Oeste e Nordeste. Principalmente, os tempos e custos são mais altos à medida em que as cidades são mais distantes das capitais. Perante os dados, é possível afirmar que a acessibilidade e a eficiência dos modos de transporte atualmente ofertadas para essas populações devem ser alvo de melhorias. Os dados utilizados como diagnóstico para um planejamento intermodal indicam não somente que algumas populações estão isoladas geograficamente, mas que a 
infraestrutura e os serviços de transporte ofertados resultam em custos e tempos de viagens superiores aos de outras regiões do país.

De fato, as áreas mais prejudicadas nos aspectos de acessibilidade e eficiência do transporte interurbano são carentes de infraestrutura (rodovias, aeroportos, ferrovias), e consequentemente, de serviços. Por outro lado, a região Norte é a que melhor explora o transporte hidroviário, com cerca de 5,2 milhões de pessoas/ano em viagens interurbanas, o que representa $6,24 \%$ da divisão modal da região. Como os tempos de viagem desse modo de transporte são elevados, o tempo de viagem ponderado pelas principais demandas das UTPs na região resultam igualmente elevados. Os dados agrupados por região evidenciam desigualdades na mobilidade interurbana do país (Tabela 4).

Tabela 4: Tempo (h) e custo ( $R \$$ ) médio ponderados pela demanda - viagens interurbanas, por região.

\begin{tabular}{lccc}
\hline & $\begin{array}{c}\text { Tempo médio ponderado } \\
(\mathrm{h})\end{array}$ & \multicolumn{2}{c}{$\begin{array}{c}\text { Custo médio ponderado das } \\
\text { ligações (R\$) }\end{array}$} \\
\hline Norte & 5,89 & $\mathrm{R} \$$ & 175,12 \\
\hline Centro-Oeste & 4,04 & $\mathrm{R} \$$ & 159,63 \\
\hline Nordeste & 3,50 & $\mathrm{R} \$$ & 114,06 \\
\hline Sudeste & 2,50 & $\mathrm{R} \$$ & 86,91 \\
\hline Sul & 2,36 & $\mathrm{R} \$$ & 86,14 \\
\hline
\end{tabular}

Um caso a se observar é o de Brasília-DF, que possui um tempo médio ponderado de 6,08 horas, e um custo médio de $\mathrm{R} \$ 305,59$, bem superior ao de outras capitais com alta integração, como São Paulo $(3,6$ h e $R \$ 163,92)$, Rio de Janeiro $(4,01$ h e $R \$ 190,68)$ ou Belo Horizonte $(4,17$ h e $\mathrm{R} \$ 126,34)$. Os dados desagregados por ligação indicam que Brasília possui forte relação e demanda significativa com todas as demais capitais brasileiras, enquanto essas capitais possui um relacionamento mais forte com cidades de seu entorno regional ou capitais mais próximas. Essa característica é associada à rede de gestão que demanda relações da Capital Federal com todo o país, e à posição geográfica que coloca Brasília praticamente equidistante de cada extremo do território, resultando em tempos e custos ponderados de viagens interurbanas elevados. 
O retrato da mobilidade interurbana nacional está bastante relacionado à disponibilidade limitada de infraestrutura e serviços. Como pode ser observado na Figura 6, das 75.057 ligações mapeadas na matriz O/D, 74.260 (98,93\%) possuem somente um modo de transporte ofertado para viagem direta (sem integração intermodal), que é majoritariamente o modo rodoviário. A exceção se dá em 190 ligações da região norte, onde o acesso disponível é somente pelos rios. Lembrando que, para essa análise, não se considera a aviação geral executiva ou táxi aéreo como um modo disponível para a população, apesar de contemplados nos valores da matriz O/D.

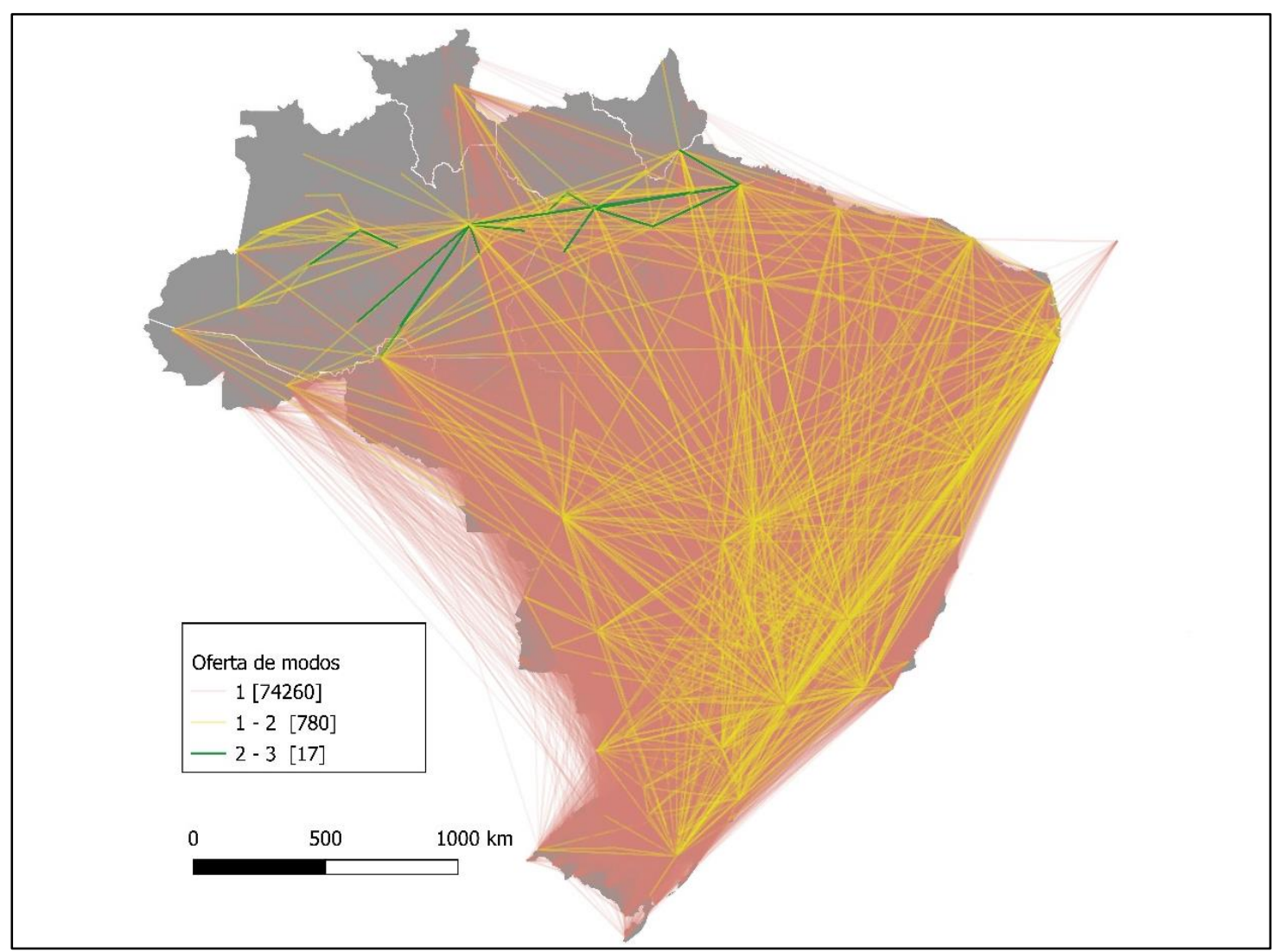

Figura 6 - Ligações interurbanas por quantidade de modos de transporte disponíveis para viagens diretas.

A disponibilidade direta é decisiva para o usuário. Para a maior parte das cidades a única forma de se iniciar uma viagem é por automóvel, e por isso o usuário tende a avaliar os impactos de custo, tempo e comodidade de realizar uma troca modal em seu percurso.

Os dados da matriz proveniente da telefonia móvel (Labtrans, 2020) apontam que 23 milhões de pessoas ( $31 \%$ das viagens interurbanas que utilizaram o transporte aéreo), também 
utilizaram o modo rodoviário como uma etapa interurbana entre a cidade de origem real da pessoa e a cidade de embarque, ou destino real e cidade de desembarque. Desconsidera-se nesse valor as viagens internas às UTPs, dadas como complemento urbano. Logo, as viagem intermodais são significativas nos deslocamentos interurbanos, o que corrobora com a necessidade de um olhar sistêmico para o planejamento dos subsistemas.

A Figura 7 apresenta as 797 ligações que possuem mais de um modo de transporte ofertado para viagens diretas, que concentram 209 milhões de viagens/ano. Nas figuras, são identificados quais modos apresentam o menor tempo, o menor custo e qual é o modo de transporte preferido para a ligação, ou seja, o que concentra a maior parte da demanda. Visualmente, é possível identificar que nem o modo de transporte preferido dos usuários são os que possuem menor tempo ou custo. $O$ transporte aéreo é o modo que apresenta o menor tempo para $85 \%$ dessas ligações, e o ônibus é a opção de menor custo para $57 \%$. Porém, os modos de transporte preferidos pelos usuários são o transporte aéreo em 49\% das ligações, seguido pelo automóvel, com $38 \%$, ônibus rodoviários com $8 \%$ e o transporte hidroviário com $5 \%$.

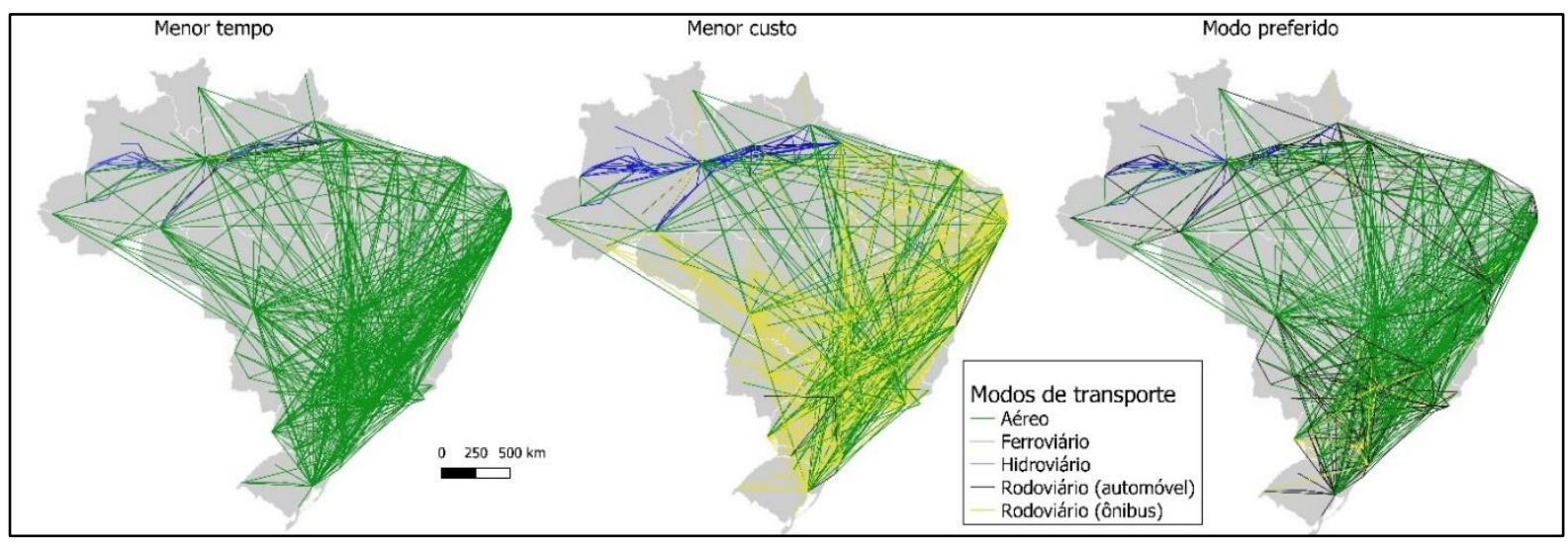

Figura 7 - Ligações interurbanas por modo de transporte de menor tempo, menor custo, e preferido pelos viajantes.

Dentro desse recorte de ligações com diferentes opções modais, $22 \%$ delas possuem o modo de transporte preferido dos usuários coincidente com o de menor tempo e menor custo, concomitantemente. Outras $32 \%$ coincidem seu modo preferido com o de menor tempo, e $11 \%$ com o de menor custo, restando ainda $34 \%$ das ligações onde o modo de transporte preferido não parece ser determinado por tais parâmetros. Isso indica que as funções de 
utilidade dos viajantes são mais complexas, e que outros fatores são levados em consideração para a decisão modal, de forma consciente ou não.

Um desses fatores tende a ser a quantidade de pessoas que viajam juntas, como as viagens em família. Enquanto para os modos de transporte coletivos (ônibus, transporte aéreo, transporte ferroviário e embarcações de transporte de passageiros), o custo aumenta de forma linear a cada pessoa que viaja acompanhada, o custo para viagens por automóvel se mantém praticamente constante, com variação marginal no combustível consumido pelo aumento do peso transportado. Ao simularmos viagens em grupos e analisarmos a coincidência dos menores custos com a predominância de demanda por modo para cada ligação, o fator de custo torna-se mais relevante a cada pessoa acrescentada, fazendo com que para um grupo de 4 pessoas, o percentual de ligações que coincidem o menor custo com a preferência da demanda pelos usuários suba de $11 \%$ para $29 \%$. Nesse cenário de grupo de quatro pessoas, o modo de transporte rodoviário por automóvel passa a ser o mais econômico para 68,5\% das ligações, enquanto em viagens individuais ele é a opção mais econômica apenas para 1,38\% delas.

Viagens interurbanas em grupo são prática comum para o sistema. De acordo com a EPL (EPL e Axiomas, 2013; apud EPL, 2020a), a ocupação média de veículos rodoviários de passeio em viagens nas principais rodovias do país é de 2,08 pessoas por veículo, com variação baixa dessa média nos Estados.

Em que pese o custo e o tempo de viagem apresentarem alguma correlação com a preferência do modo de transporte nas viagens diretas com oferta de mais de um modo, a distância da viagem parece ser um fator determinante para a escolha do modo. Ao analisarmos as ligações onde há concorrência entre os dois principais modos desse recorte, o transporte por automóvel e o transporte aéreo, nos deparamos com nítida tendência de migração da demanda do automóvel para o transporte aéreo conforme se aumenta a distância da ligação. A Figura 8 apresenta os dados e as linhas de tendência logarítmicas dessa relação, cujo ponto de inflexão das duas curvas está em exatos $750 \mathrm{~km}$. Situação onde há tendência de distribuição igual da demanda entre os modos. Por outro lado, após 1350 km existe nítido distanciamento entre as curvas, com concentração da demanda no transporte aéreo acima de $70 \%$. O inverso ocorre para o transporte rodoviário nas ligações de até $425 \mathrm{~km}$. 


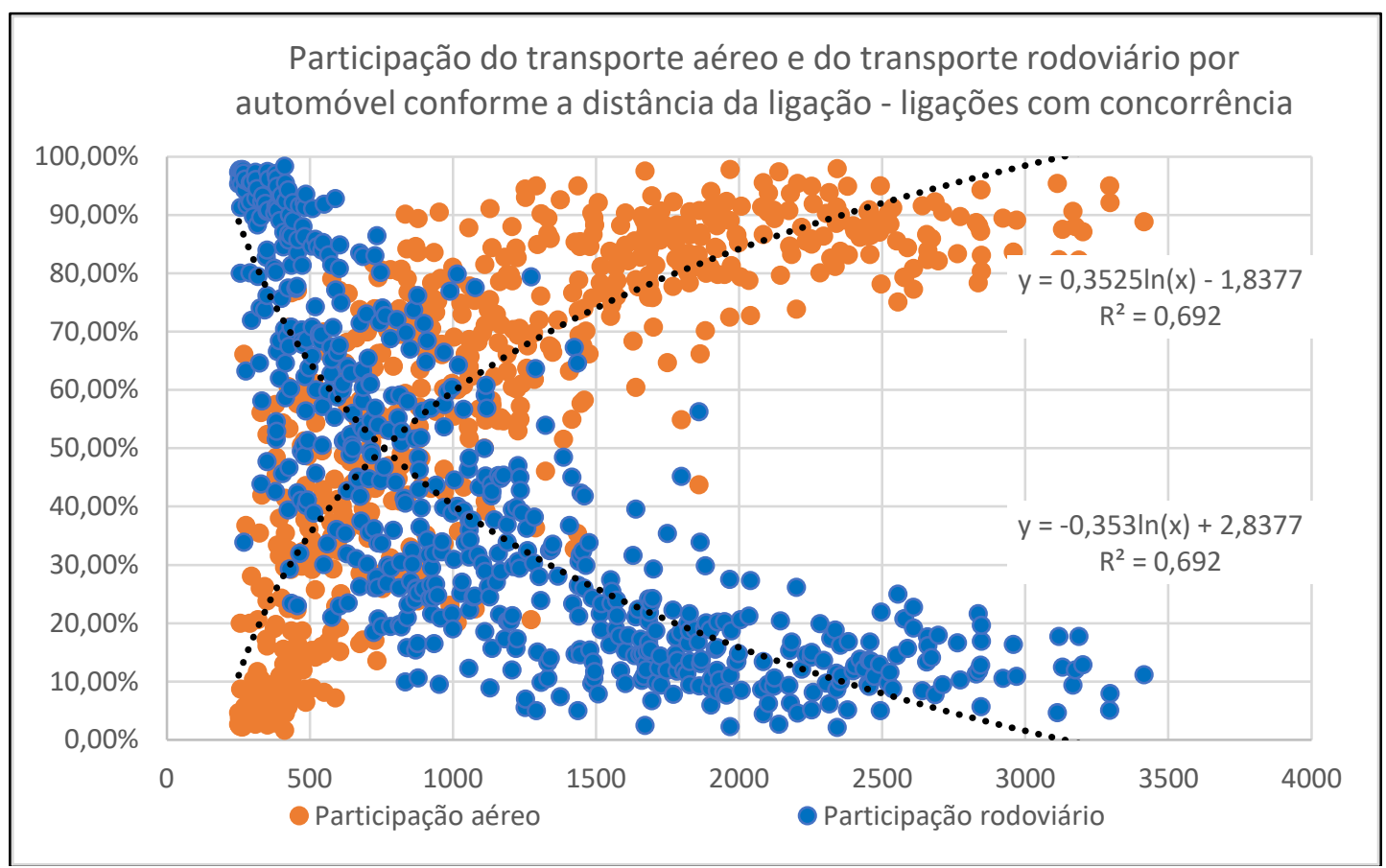

Figura 8 - Participação do transporte aéreo e do transporte rodoviário por automóvel conforme a distância da ligação - ligações com concorrência.

Verifica-se então, que entre 425 e $1350 \mathrm{~km}$ é onde está o potencial concorrencial entre o transporte aéreo e o transporte rodoviário por automóvel. O mesmo não ocorre quando comparamos os modos de transporte coletivos: aéreo e ônibus. A distribuição de demanda entre esses dois modos nas ligações onde há oferta de ambos parece ser mais aleatória em relação à extensão da ligação. O que se observou, porém, é uma correlação entre a proporção da demanda que se divide entre esses modos, com a relação entre os custo do transporte por ônibus/custo do transporte aéreo, sendo o coeficiente de correlação (R) de -0,63 e de determinação (R2), de 0,51 para uma curva exponencial negativa. Logo, verifica-se que quando o custo da viagem por ônibus é muito menor que o custo aéreo, existe tendência de concentração da demanda para o modo coletivo rodoviário. A equação da curva de tendência aponta que caso o custo do transporte rodoviário seja cerca de $30 \%$ do custo do transporte aéreo, existe tendência de concentração da demanda acima de $50 \%$ nos ônibus.

A diferença das relações entre modos rodoviário por automóvel, por ônibus e o transporte aéreo, indicam que tentar generalizar as funções de utilidade para os viajantes do transporte interurbano no Brasil é hipótese arriscada. Enquanto para algumas ligações e parcelas da população o fator custo parece ser indicativo para uma decisão, para outra parte, a distância 
da viagem é determinante. De todo modo, ao olharmos a escala mais ampla da rede de transporte interurbana doméstica de pessoas no Brasil, se sobressai a limitação de oferta de infraestrutura e serviços como condutor da mobilidade.

Em relação ao número de viagens per capita, na média nacional, o brasileiro viajou 9,77 vezes em 2017, mas esse número varia geograficamente (Figura 9), com valores baixos de viagens/habitante na maior parte do Norte, Nordeste e Centro-Oeste, e maiores nas UTPs mais ao Sudeste e Sul.

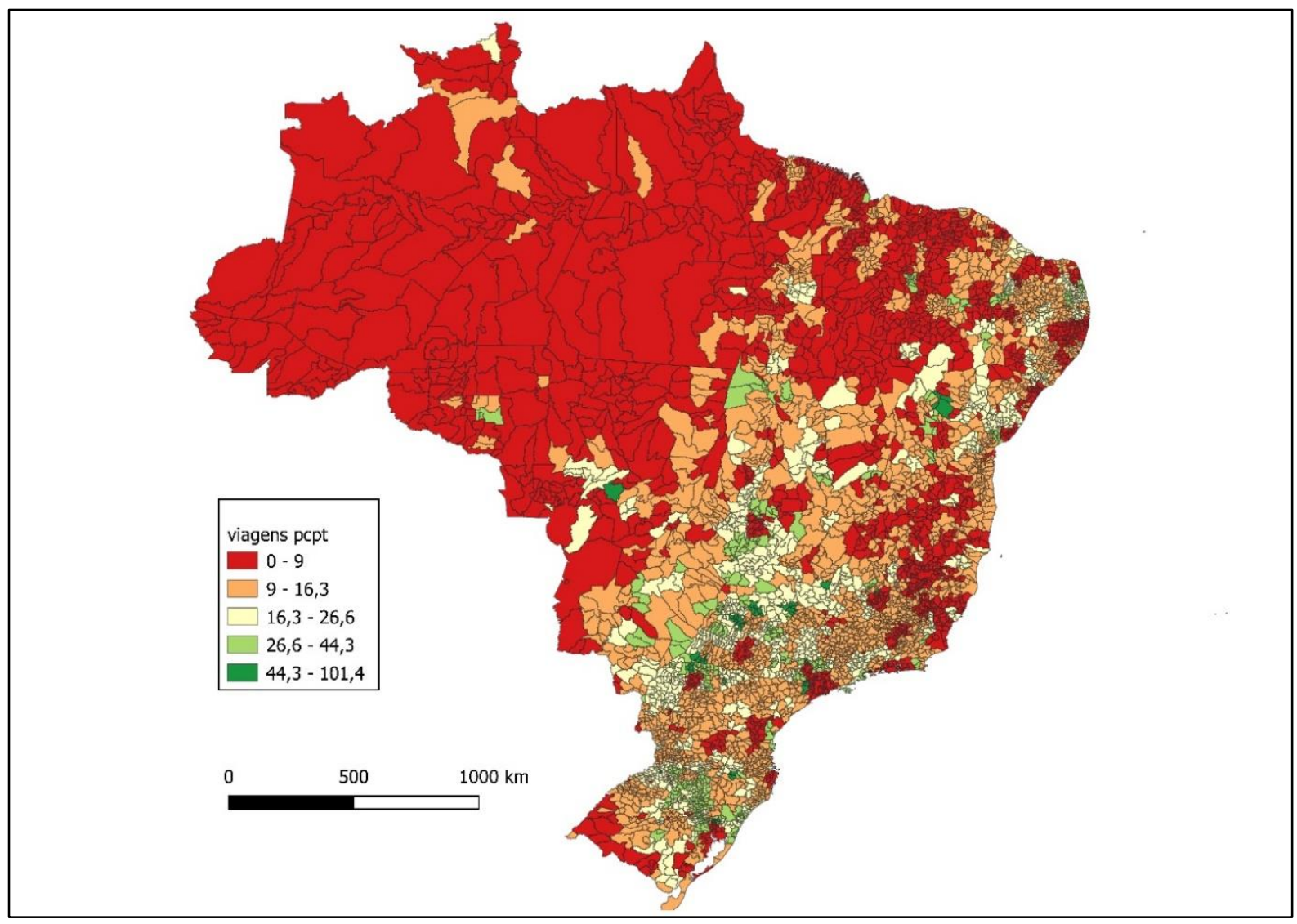

Figura 9 - Viagens per capita por UTP.

As viagens per capita não apresentam correlação com o PIB ou PIB per capita da UTP (-0,03 e 0,29 , respectivamente). O que foi observado é que as UTPs com maiores valores de viagens/habitante são as que não são capitais ou não compõem regiões metropolitanas, mas que por outro lado, possuem grande oferta de infraestrutura e serviços interurbanos (rodovias, aeroportos regionais e/ou linhas de ônibus). Uma hipótese que o resultado indica é que essas populações necessitam se deslocar mais, justamente para acesso à serviços e atividades não disponíveis na localidade e ofertadas nas grandes aglomerações urbanas 
(incluindo as atividades de negócios, lazer e visitas familiares), e ao mesmo tempo, encontram um conjunto de infraestrutura e serviços que permitem esses deslocamentos. Os custos e tempos médios de deslocamentos dessas UTPs são relativamente baixos, indicando um casamento entre a demanda e a oferta.

Ao traçarmos as viagens per capita por modo de transporte, chega-se os resultados apresentados na Figura 10.

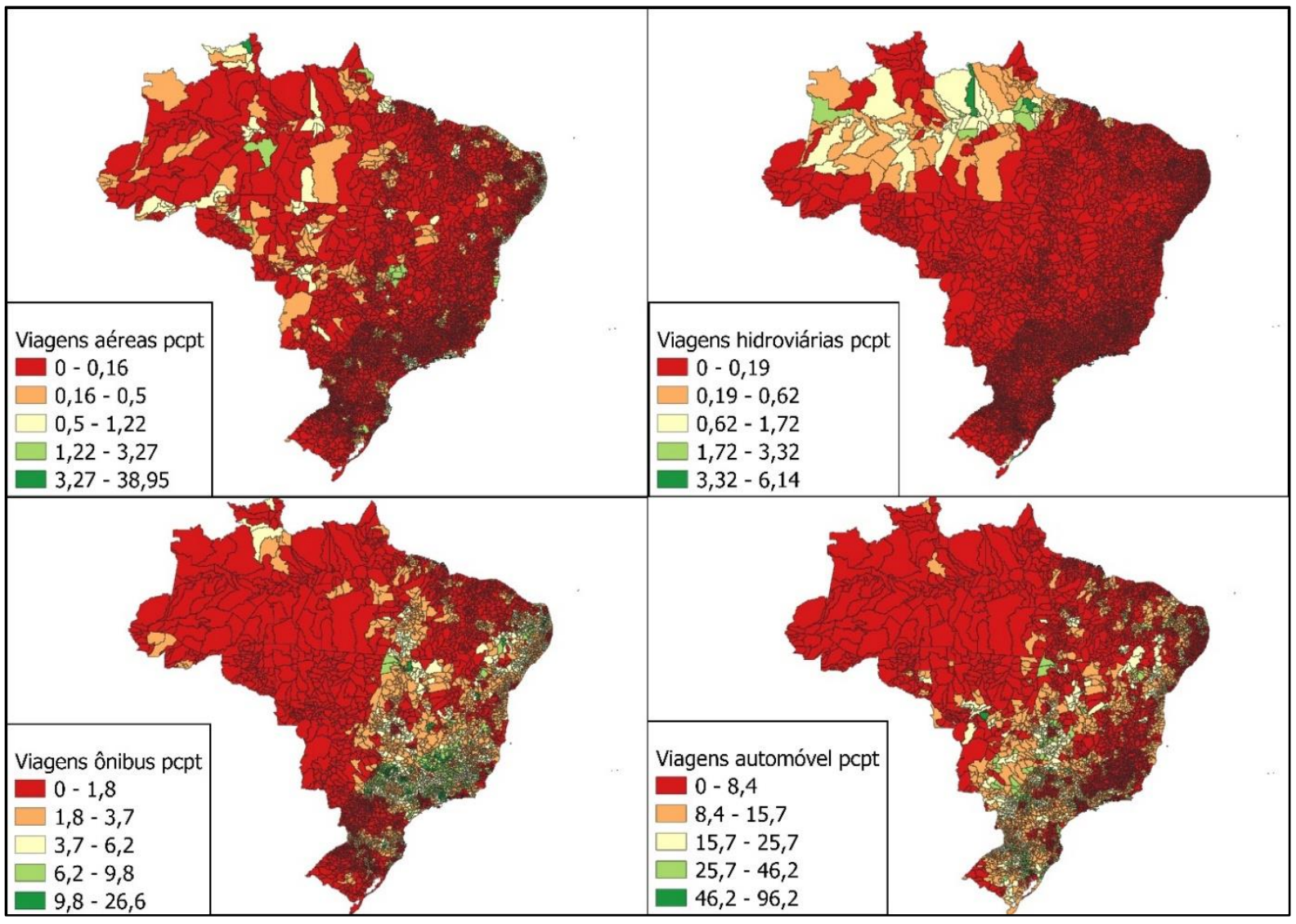

Figura 10 - Viagens per capita por modo de transporte

Os maiores índices de viagens aéreas por habitante concentram-se nas capitais, visto a concentração de maior oferta de destinos, concorrência entre companhias aéreas e, consequentemente, menores custos para esse deslocamento em relação às localidades que possuem aeroportos regionais. A UTP com maior índice é Fernando de Noronha-PE, com 38,95 viagens aéreas ao ano. Porém, esse valor é um resultado particular, devido à baixíssima população residente e à única forma de acesso àquela ilha. As demais UTPs apresentam valores de 0 a 4,5 viagens ao ano. 
As viagens per capita para o modo hidroviário concentram seus maiores índices nas localidades do Amazonas e Pará distantes das capitais, e indicam que esse modo é o principal ou único modo para viagens interurbanas nessas localidades.

Em relação às viagens per capita por ônibus, é possível identificar geograficamente que os eixos onde concentram-se os maiores índices formam uma contiguidade ligando as cidades no litoral do Nordeste ao Sudeste, e este ao eixo Norte até o Maranhão, demonstrando a capilaridade desse serviço e o papel social de integração nacional, principalmente para as cidades distantes das capitais. O comportamento é diferente do modo rodoviário por automóvel, que concentra seus maiores índices no interior do Goiás, interior de São Paulo, e nas cidades da região Sul longe das capitais.

\section{Conclusões}

O presente trabalho busca expor como a visão sistêmica e integrada do transporte interurbano pode contribuir para a melhoria das ações resultantes do planejamento. 0 diagnóstico limitado à modos de transporte e/ou à limites político-institucionais, pode trazer percepções equivocadas da mobilidade dos usuários, pois na visão deles, o conjunto de infraestruturas e serviços para os deslocamentos interurbanos formam um único sistema. Além disso, limitam a visão real de concorrência ou complementariedade intermodal. A partir de estudos voltados para a visão mais completa dos deslocamentos interurbanos, pode-se desenvolver ações conforme o âmbito de atuação dos diferentes entes da gestão pública envolvidos, em cada subsistema, buscando a complementariedade e o melhor nível de serviço à população.

Os resultados apontaram mobilidade distinta para diferentes localidades. A acessibilidade ofertada para a população, em termos de impedâncias para as principais viagens demandadas, como o tempo, e a eficiência desses deslocamentos, medida pelo seu custo, apresentam diferenças regionais significativas, assim como foi observado que os usuários também pesam por diferentes parâmetros para seus deslocamentos e escolhas. Uma forma de utilização efetiva dos resultados aqui apresentados no planejamento, é a busca de soluções para nivelamento desses indicadores nas diferentes regiões, visto a relevância desse sistema que movimenta mais de 2 bilhões de pessoas ao ano. 
O diagnóstico apresentado é útil tanto para o planejamento do setor público, nas diferentes esferas, como para a iniciativa privada. Os dados segregados por modo de transporte ou esfera administrativa disponíveis até então, não permitiam adequada análise de potenciais de competitividade. Neste trabalho observou-se, por exemplo, que a competitividade entre modos ocorre em poucas ligações, e predominantemente entre o transporte aéreo e 0 automóvel, nas ligações entre 425 e 1350 km.

Os dados utilizados no presente trabalho tiveram origens em diferentes fontes, mas a visão ampliada da mobilidade interurbana brasileira seria bastante dificultada sem o uso do big data da telefonia móvel, demonstrando o potencial dessa tecnologia para o planejamento e estudos em transportes, e a eficiência dessa alternativa perante pesquisas tradicionais.

Existem ainda limitações para uma compreensão adequada da mobilidade interurbana e seus aspectos, principalmente, do ponto de vista dos usuários. Com os dados obtidos é possível a calibração de funções de utilidade para escolha modal, trabalho previsto como continuidade deste. Porém, já foi possível observar que as escolhas são mais complexas que em sistemas de transporte urbano ou para o transporte de cargas, que majoram o custo financeiro e o tempo dentro de suas funções. Considerando que em $34 \%$ das ligações com mais de um modo de transporte ofertado para viagem direta, a demanda predominante não é conscidente com os modos de menor custo, e nem de menor tempo, indica-se que a distância da viagem, a quantidade de viajantes juntos, ou fatores mais subjetivos como o conforto, a conveniência, a preferência pré-determinada ou o prazer por dirigir ou voar, influenciam nas decisões, demandando mais informações para conhecimento desses aspectos.

As análises do modo ferroviário ficam comprometidas para a visão sistêmica, pois somente duas ferrovias realizam viagens interurbanas no Brasil. Porém, é essencial que o modo seja explorado como alternativa para projetos futuros, pois observou-se corredores de passageiros com demandas potenciais (como a ligação entre São Paulo e Rio de Janeiro, ou São Paulo e Santos), e ainda, que esse modo de transporte possui o menor custo médio ponderado por passageiro/km, sendo de $R \$ 0,40$, contra $R \$ 0,66$ para o automóvel, $R \$ 0,69$ para os ônibus, $\mathrm{R} \$ \mathbf{0 , 9 8}$ para o transporte aéreo e $\mathrm{R} \$ 1,00$ para o transporte hidroviário. 


\section{Referências}

Alexander, L., S. F. Jiang, M. Murga, and M. C. Gonzalez (2015). Origin-destination trips by purpose and time of day inferred from mobile phone data. Transp. Res. Part C: Emerging Technol. 58: 240-250. https://doi.org/10.1016/j.trc.2015.02.018.

ANAC (2020a). Dados estatísticos. Agência Nacional de Aviação Civil. Disponível em: https://www.anac.gov.br/assuntos/dados-e-estatisticas/dados-estatisticos/dados-estatisticos . Acesso em fevereiro de 2020 .

ANAC (2020b). Tarifas Aéreas. Agência Nacional de Aviação Civil. Disponível em: https://www.anac.gov.br/assuntos/setor-regulado/empresas/envio-de-informacoes/relatorio-de-tarifasaereas-domesticas. Acesso em fevereiro de 2020.

ANATEL (2020). Dados abertos. Agência Nacional de Telecomunicações. Disponível em: https://www.anatel.gov.br/dados/component/content/article/125-chamadas/280-dados-abertos. Acesso em junho de 2020.

ANTAQ e UFPA (2018). Caracterização da oferta e da demanda do transporte fluvial de passageiros e cargas na região Amazônica. Agência Nacional de Transportes Aquaviários e Universidade Federal do Pará. Disponível em: http://portal.antaq.gov.br/index.php/caracterizacao-da-oferta-e-da-demanda-do-transporte-fluvial-depassageiros-na-regiao-amazonica. Brasília.

ANTT (2011). Licitação de serviços de transporte rodoviário interestadual de passageiros - Plano de outorga. Projeto da rede nacional de transporte rodoviário interestadual de passageiros, PROPASS Brasil - serviços operados com ônibus do tipo rodoviário. Agência Nacional de Transportes Terrestres - ANTT. Brasília.

ANTT (2018). Dados operacionais do transporte interestadual de passageiros. Agência Nacional de Transportes Terrestres. Disponível em: http://www.antt.gov.br/passageiros/Dados_Operacionais . Acesso em abril de 2018.

ANTT (2020a). Sistema de Monitoramento do Transporte Rodoviário Interestadual e Internacional Coletivo de Passageiros - MONITRIIP. Agência Nacional de Transportes Terrestres. Disponível em: https://dados.antt.gov.br/group/passageiros . Acesso em fevereiro de 2020.

ANTT (2020b). Legislação do Transporte Rodoviário Interestadual de Passageiros. Agência Nacional de Transportes Terrestres. Disponível em: http://www.antt.gov.br/passageiros/Legislacao_do_Transporte_Rodoviario_Interestadual_de_Passageiros.ht $\mathrm{ml}$. Acesso em: fevereiro de 2020.

Bates, J. (2000). History of demand modelling. In Hensher, D.A and Button, K.J. [edit.] Handbook of transport Modelling. Pergamon, Elsevier. ISBN: 0080435947

Calabrese F.; Diao M.; Lorenzo G. D.; Ferreira J.; Ratti C. (2013). Understanding individual mobility patterns from urban sensing data: A mobile phone trace example. Transportation Research Part C: Emerging Technologies, v. 26, p. 301-313, 1.

Cascetta, E.; Nguyen, S. (1988); A unified framework for estimating or updating origin/destination matrices from traffic counts. Transportation Research Part B, v. 22, n. 6, p. 437-455.

Crozet, Y. (2009), The Prospects for Inter-Urban Travel Demand. OECD/ITF Joint Transport Research Centre Discussion Papers, No. 2009/14, OECD Publishing, Paris. https://doi.org/10.1787/5kmmr3hqt4f6-en.

DECEA (2016). Extrato do Banco de Informações do Movimento de Tráfego Aéreo (BIMTRA) do Departamento de Controle do Espaço Aéreo - DECEA. Comando da Aeronáutica. 2016.

Dinwoodie, J. (2001). Handbook of Transport Modelling, David A. Hensher, Kenneth J. Button (Eds.). Pergamon, Amsterdam, 2000, 690 pages, \$162/140 euros, ISBN 008043594 7. Journal of Transport Geography - J TRANSP GEOGR. 9. 303-304. 10.1016/S0966-6923(01)00023-0.

EPL (2020a). Apresentações de divulgação de resultados parciais do Plano Nacional de Logística - PNL. Empresa de Planejamento e Logística S.A. Disponível em: https://www.epl.gov.br/matrizes-de-origem-e-destino-parapnl-2035-sao-apresentadas-em-webinar- Acesso em: setembro de 2020 
EPL (2020b). Observatório Nacional de Transporte e Logística - ONTL. Empresa de Planejamento e Logística S.A. Disponível em: https://www.ontl.epl.gov.br Acesso em: fevereiro de 2020.

EPL (2020c). Apresentações do Webinar - Rodovias No Plano Nacional de Logística. Custos de Transporte para Rodovias no PNL. Empresa de Planejamento e Logística S.A. Disponível em: https://www.youtube.com/watch?v=q6lyPXxNKtl . Acesso em setembro de 2020.

EPL (2021). Plano Nacional de Logística 2035 - Versão para Consulta Pública. Empresa de Planejamento e Log'sitica S.A. Disponível em: https://www.gov.br/participamaisbrasil/plano-nacional-de-logistica-pnl-2035 . Acesso em junho de 2021.

IBGE (2007). Regiões de influência das cidades. Instituto Brasileiro de Geografia e Estatística. Rio de janeiro.

IBGE (2016). Arranjos populacionais e concentrações urbanas. Instituto Brasileiro de Geografia e Estatística. Rio de janeiro.

IBGE (2017a). Redes e Fluxos do Território - Ligações Rodoviárias e Hidroviárias 2016. Instituto Brasileiro de Geografia e Estatística. Rio de Janeiro.

IBGE (2017b). Divisão regional do Brasil em regiões geográficas imediatas e regiões geográficas intermediárias: 2017 / IBGE, Coordenação de Geografia. - Rio de Janeiro : IBGE, 2017. 82p.

Iqbal, M. S.; Choudhury C. F.; Wang, P.; González, M. C. (2014). Development of origin - destination matrices using mobile phone call data. TRANSPORTATION RESEARCH PART C, v. 40, p. 63-74, 2014. Disponível em: <http://dx.doi.org/10.1016/j.trc.2014.01.002>.

Labtrans (2019). Relatório de Metodologia - Estimativa de fluxos de passageiros do transporte aéreo. Laboratório de Transportes e Logística - Labtrans. Universidade Federal de Santa Catarina - UFSC. Florianópolis.

Labtrans (2020). Dados da matriz Origem Destino entre UTPs. Laboratório de Transportes e Logística Universidade Federal de Santa Catarina / UFSC. Disponível em: https://horus.labtrans.ufsc.br/gerencial/\#MatrizOd . Acesso em: setembro de 2020.

Lieshout, R. (2012). Measuring the size of an airport's catchment area. Journal of Transport Geography, v. 25, p. 27-34.

Mamei M.; Bicocchi N.; Lippi M.; Mariani S.; Zambonelli F. (2019). “Evaluating Origin-Destination Matrices Obtained from CDR Data." Sensors (Basel, Switzerland) vol. 19,20 4470. doi:10.3390/s19204470

MInfra (2020). Pesquisa de Satisfação do Passageiro. Secretaria Nacional de Aviação Civil/Ministério da Infraestrutura. Disponível em: https://www.infraestrutura.gov.br/pesquisa-satisfacao.html. Acesso em: fevereiro de 2020.

MTPA (2018a). Política Nacional de Transportes - PNT. Portaria no 235, de 28 de março de 2018. Institui a Política Nacional de Transportes e estabelece princípios, objetivos, diretrizes e instrumentos para o setor de transportes. Ministério dos Transportes, Portos e Aviação Civil. Brasília.

MTPA (2018b). Extrato de Execução Descentralizada, referente ao Termo de Execução Descentralizada firmado entre o Ministério dos Transportes, Portos e Aviação Civil e a Universidade Federal de Santa Catarina. Publicado no D.O.U № 81, em 27 de abril de 2018, seção 3. ISSN 1677-7069.

MTPA (2018c). Plano Aeroviário Nacional 2018 -2038. Metodologia e resultados. Ministério dos Transportes, Portos e Aviação Civil. Brasília. Disponível em: www.infraestrutura.gov.br/pan.

Nabavi, A.; Olteanu-Raimond, A.; Perret, J. (2015). Investigating the mobile phone data to estimate the origin destination flow and analysis; case study: Paris region. Transportation Research Procedia, v. 6, p. 64-78. Disponível em: http://dx.doi.org/10.1016/j.trpro.2015.03.006

Philbrick, A.T.C. (1971). Transportation gravity models. University of Queensland, Dept. of Civil Eng, 1971.

SAC \& EPL (2015). Pesquisa Origem Destino nos aeroportos brasileiros. Secretaria de Aviação Civil e Empresa de Planejamento e Logística S.A. Disponível em: www.aviacao.gov.br/obrasilquevoa.

Silva, L. R.; Vilela, M. L. ; Yamashita, Y. (2019). Ampliando a compreensão da mobilidade interurbana no brasil Da concepção do sistema à construção de uma matriz origem destino. In: 33o Congresso de Ensino e Pesquisa 
em Transportes, 2019, Balneário Camburiú-SC. Anais do 330 Congresso de Ensino e Pesquisa em Transportes, 2019. v. I.

Silva, L. R.; Holanda, F. (2019). Space Syntax in a National Scale: A case-study on inter-urban network transportation in Brazil. In: International Space Syntax Symposium, 12, 2019, Beijing. Proceedings. Beijing: Beijing Jiao Tong University, 2019. p. 1-17.

Spiess, H. (1987). A maximum likelihood model for estimating origin-destination matrices. Transportation Research Part B, v. 21, n. 5, p. 395-412.

Telefônica Data Unit (2019). Relatório de Metodologia. Desenvolvimento de uma matriz O/D de passageiros em âmbito nacional para identificação dos desejos de viagem contemplados ou não pelo transporte aéreo, utilizando como base as unidades de planejamento territorial. Telefónica Digital España.

Vale (2020a). Informações da Estrada de Ferro Carajás. VALE. Disponível em: http://www.vale.com/brasil/PT/business/logistics/railways/Passenger-Train-Service-

Carajas/Paginas/default.aspx. Acesso em fevereiro de 2020.

Vale (2020b). Informações da Estrada de Ferro Vitória Minas. VALE. Disponível em: http://www.vale.com/brasil/PT/business/logistics/railways/Passenger-Train-ServiceCarajas/Paginas/default.aspx. Acesso em fevereiro de 2020.

Van Z., Henk J.; Willumsen, L. G. (1980). The most likely trip matrix estimated from traffic counts. Transportation Research Part B: Methodological, v. 14, n. 3, p. 281-293, 1980.

Wang, Y.; Correia, G.A.; de Romph, E. (2015). National and Regional Road Network Optimization for Senegal Using Mobile Phone Data. In Proceedings of the Netmob 2015, Cambridge, MA, Estados Unidos, 8-10.

Woolridge, J. M. (2010). Econometric Analysis of Cross Section and Panel Data. Cambridge, Massachusetts: The MIT Press.

Yai T., Fujisaki K., Itoh R., Kariyazaki K., Kume H., Pan H., Rothengatter W., Suzuki A., Tomari N. (2015). Intercity Transport Policy and Planning System: International Comparison Between the EU, USA, China and Japan. In: Intercity Transport and Climate Change - Strategies for Reducing the Carbon Footprint. Chapter 2. XIV, 280 p. 